\title{
Cultivation of Ability of Talents in Textile Art Design Specialty from the Perspective of Market Situation
}

\author{
Dongdong Li \\ Henan Institute of Engineering \\ Zhengzhou, China 451191
}

\begin{abstract}
Continuous development of technology and productivity and change of new printing methods and forms lead to the situation that traditional teaching of textile art design specialty has been unable to meet the requirement of market in the new period for ability of students in textile design specialty. It is significant problem faced by textile art design specialty about how talent cultivation of textile design specialty can get closer to operation mode of marketization and how to let students just graduating from textile design specialty faster adapt to requirements of marketization. This article gets to know abilities required by the market for talents in textile design specialty through field investigation, thereby teachers can training students to obtain a variety of abilities on purpose in teaching.
\end{abstract}

\section{Keywords — textile art design; market; ability; cultivation}

\section{INTRODUCTION}

Improvement of the whole situation of home textiles and emergence of new craft and methods of production make design companies related to textile design specialty spring up like mushrooms, such as home textiles design companies, carpet design companies, wallpaper design companies, cushion design companies and automobile textile design companies. Employment situation of students in textile art design specialty becomes better and better, but students just graduating from textile art design specialty cannot meet the requirements of companies for abilities of talents. They need training by companies again. However, at present, many companies prefer to employ designers with practical experience rather than put energy in training this year's graduates. It requires that the talent cultivation of textile art design specialty shall meet the requirements of market to the furthest. According to experience accumulated in many years of teaching in textile design specialty, the author continuously contacts and gets to know the market and analyzes comprehensive requirements of the market for abilities of talents in textile design specialty, thereby trains students to grasp a variety of abilities required on purpose in teaching process.

\section{CULTURAL QUALITY AND PROFESSIONAL THEORY}

Modern enterprises pay increasingly high attention to enterprise culture, which has become main selling points of many products. Designers must deeply understand culture of the enterprise. If they have the opportunity to establish companies of their own and create brands, they shall attach importance to development of enterprise culture and brand culture. China has very excellent and profound cultural heritages. There are many things remained to be explored by us, but we neglect quite a number of them. We can combine with local characteristics to develop local textile brands. For example, it is well-known that Luoyang in Henan province is ancient capital of nine dynasties with very rich cultural connotation. Cultural objects with characteristics of Central Plains excavated in Luoyang are too numerous to mention one by one. Peony in Luoyang is number one in the world and can serve as source of designers to design and develop new brands. But it is often neglected by designers, who often plagiarize design of foreign countries instead of excavate Chinese traditional culture. On the other hand, in order to excavate Chinese traditional culture, they should understand and research it, so it is necessary to strengthen cultivation of their cultural quality.

It is of great importance to grasp specialized theoretical knowledge. Specialized basic theories in design field shall be learned solidly, such as plane composition, color composition, basic pattern and creative pattern. Students shall learn to apply them reasonably. During the period of teaching, it is found that many students lack the ability to analyze works of textile design. Under many circumstances, students just think the works is very beautiful, but they cannot tell the reason of its beauty. The analysis on works of textile design shall comprehensively apply basic theories learned and it should be specific. We can start with modeling, color, and layout structure and expression method of elements. The analysis on modeling of elements should combine with the theory of dot, line and plane in plane composition, theory of density contrast, method and repetition; analysis on color should combine with theory of color composition and contrast relation of main elements of color, such as lightness, hue, purity and cool and warm color; on layout structure, we should be proficient in basic arrangement methods such as two-dimension series and quadrilateral continuity and learn special arrangement structures in textile design such as abutment joint and jumper connection; we should grasp reasonable application of expression methods in textile design, such as flat painting, plane split, falling stroke, shading, silhouette and inscription rubbing. 


\section{ABILITY OF CREATIVE THINKING}

Textile art design belongs to the category of design. The creation of design cannot do without creative thinking of designers. So in teaching process, teachers should strengthen training for students' creative thinking. I once organized students to participate in China International Home Textiles Design Competition. The competition requires the workers must be original works. Some students draw a lot of works but none of them is qualified because most works are copied from others. With development of economy and improvement of aesthetics, modern people are inclined to favor individuation, which is also suitable for home textiles. Excellent home textiles designers must learn to extract design elements from life and nature and design outstanding original works.

In the process of teaching, teachers can use scientific thinking methods to train students and let students develop new habits and apply them in specific design practice, train students' original ability, break through original thinking pattern, improve their consciousness of innovation and increase creativity in design. They can train students' abilities of contrary thinking, divergent thinking, converged thinking and imaginary thinking, let students break the confinement of thinking and walk out of the mire of imitation without originality.

Thinking forms often used in design include: inspiration thinking, addition thinking, subtraction thinking and reverse thinking, divergent thinking. Frequent training of thinking forms helps to increase the quality and speed of design works.

Inspiration thinking: Inspiration refers to a thinking form of precipitate understanding for problems with the help of intuitive feelings. It is one of the most important forms in creative thinking. Its emergence needs long-run knowledge accumulation, good mental state and long-term concentrative thinking and exploration.

Reverse thinking: It refers to the thinking form to solve problems through reversing direction of thinking and using opposite thinking methods. It has prominent innovativeness and abnormal creativity.

Divergent thinking: It refers to the thinking pattern in diffusion state showed by the brain in thinking, with broad view of thinking and multi-dimensional shape.

\section{PROFESSIONAL FREEHAND SKETCHING ABILITY}

Previous textile art design completely relies on freehand sketching. With popularization of computer, designers are often attracted by rapid and convenient computer design and forget the importance of freehand sketching on textile art design, which carries out artistic modeling instead of using computers: Forms and design of beauty constructed by freehand sketching have a large number of perceptual factors of human beings, which is the most suitable for manifestation of artistic beauty. The training for ability of freehand sketching has high requirements for students' aesthetics and technology. Training of freehand sketching can train students' acute observation ability, strong analytical ability and exquisite expressive ability. Their eyes, brains and hands participate in it and improve the whole creativity. The way of freehand sketching can lay solid foundation for professional modeling.

From the perspective of results showed by design, in the design process of freehand sketching, different texture of paper and intensity of stroke have unique beauty. Modern wallpaper pays attention to expression of texture. When employing graduates, companies attach importance to professional freehand sketching ability. Many well-known design companies specially set up freehand sketching design department, in order to reserve effect and uniqueness of special texture of freehand sketching. Therefore, in basic design training of textile design specialty, students must strengthen training of professional freehand sketching ability, especially in freshman year and sophomore year.

At present, the elements of freehand sketching mainly focus on expression of watercolor and effect of texture. Therefore, in freshman year and sophomore year, it is necessary to strengthen the expression of watercolor. They can strengthen freehand sketching of watercolor and expression of texture effect, especially practice of expression methods of watercolor flowers from teaching of courses such as sketch course and Chinese painting in freshman year and decoration fundamentals and decorative painting in sophomore year.

\section{ABILITY TO OPERATE PROFESSIONAL COMPUTER SOFTWARE}

The operation of computer software is of vital importance for textile art design specialty. The efficiency of traditional freehand sketching method is low. For example, traditional color separation in printing relies on freehand sketching. In design works, each color must be showed on one color separation draft, which costs more time with low efficiency and low quality of ganging up. Computer software of color separation shortens time and improves efficiency and quality of ganging up. Besides, computer software has increasingly rich functions and provides techniques, effects and filter, which are beyond the reach of traditional freehand sketching.

At the present stage, computer software required by marketization for students of textile art design specialty mainly includes the following kinds:

\section{A. Photoshop, Illustrator, Coreldraw}

When employing students, most companies require them to skillfully master graphic design software such as Photoshop, Illustrator and CorelDraw. Photoshop is the software to draw and deal with bitmap and has very extensive application. It is used by textile design specialty to design patterns and modify scanned picture of freehand sketching. Illustrator and CorelDraw are software to draw and dispose vector diagram. They are not influenced by resolution ratio, so when printing, we can randomly magnify or shrink patterns without influencing the definition of pictures. They must be mastered by students of textile art design specialty.

\section{B. Related Professional Software}

Textile art design specialty is influenced by techniques from patterns to finished products. If a design drawing uses 
printing process, it is necessary to use related software to do color separation treatment. If using embroidery craft, it must use embroidery software to design acupuncture therapy and color thread. If using jacquard pattern craft, it must use jacquard pattern software to design organization structure of different color threads.

Students shall master the following related professional software:

- traditional printing software: Jinchang, Qianselong and Honghua. Traditional printing needs tracing of drawing and color separation. The software is very excellent in tracing of drawing and color separation. Honghua software is very convenient and fast in designing effect picture of home textile fabrics.

- embroidery software: Tajima, Wilcom, Fuyi and Texhong.

- jacquard pattern software: Feisuo electronic jacquard CAD system, ZDJW pattern weaving CAD, blue fox Texcelle.

- carpet design software: NEDGRAPHICS.

The learning of software shall base on mastering handpainted design and understanding related crafts, so it should carried out in senior grades of textile art design specialty. In order to become designers of textile art design specialty that can meet the requirements of the market, except for understanding textile craft, students had better learn software operation corresponding to craft to conform to the requirements of marketization.

When operating software, they should also pay attention to application of drawing board. The author pays a visit to many home textiles design companies and finds each designer in companies has drawing board. Using drawing board to design can improve flexibility of operation and greatly save time. A student who is going to graduate goes to a company to apply for a job and is required to use drawing board to make effect picture. He loses the job opportunity because he never uses drawing board.

\section{UNDERSTANDING THE PROCESSES}

Textile design specialty has process requirements in pattern and production of products. Different craftsmanship requires different characteristics of pattern design. To adapt to market needs, we should understand main technological process and requirements for patterns in textile design.

Main processes of textile design specialty mainly have printing, jacquard weave and embroidery pattern. Printing process includes flat screen printing, rotary screen printing and roller printing in traditional printing and heat transfer printing and digital jet printing in modern printing. The former will limit the number of colors in pattern design and have strict requirement for ganging up. The latter doesn't have limitation for number of colors. Jacquard weave process refers to ridge design formed by warp and weft. When making design drawing, we should pay attention to organization structure of warp and weft. Embroidery pattern refers to a method to apply needlework to existing textile and thread according to requirements of design drawing and organize embroidery threads into various patterns and colors through manipulating needle. It requires students to clearly know acupuncture therapy of embroidery patterns in design drawing.

All in all, if students of textile art design specialty want to obtain abilities required by companies, it requires teachers to pay attention to training students' abilities in teaching process Cultural quality and professional theoretical knowledge guarantees breadth of textile design. Creative thinking ability guarantees originality of design. Strong ability in freehand sketching guarantees expression of textile design. Software operation ability and understanding of processes guarantees timeliness and feasibility of craft production. With these abilities, in information era and economic globalization environment, students of textile art design specialty can use novel design originality, rapid market information and perfect products to remain invincible.

\section{REFERENCES}

[1] Yin Dingbang, Introduction to Design, Hunan Science and Technology Press, 1999

[2] Gong Liuchao. Clothing, Textile Art Design, Huashan Literature and Art Publishing House, 2002

[3] Jia Jingsheng, Computer and Textile Art Design, Tsinghua University Press, 2004 